\title{
Hans-Georg Gadamer en die Ou Testament
}

J H le Roux

(Universiteit van Pretoria)

\section{ABSTRACT}

\section{Hans-George Gadamer and the Old Testament}

Some aspects of Gadamer's hermeneutics are discussed below: his view on method, the finiteness of being human, the value of prejudices and so forth. With Gadamer's help we are also able to think anew about our South African Old Testament tradition. He has perspectives and concepts which can help us to reword the basic questions of Old Testament scholarship. Of course, Gadamer is but one possibility, but he was one of the most important thinkers of the twentieth century. Whoever struggles with him also gains insight into the hermeneutical perspectives of the twentieth century.

\section{INLEIDING}

Hans-Georg Gadamer is op 14 Maart 2002 oorlede. Hy was 'n honderd en twee jaar oud. Gadamer het die unieke voorreg gehad om die ganse twintigste eeu deur te leef en te ervaar. Hierdie eeu se hoogte- en dieptepunte het sy denke ingrypend beïnvloed. Sy lang lewe het hom ook op 'n ander manier bevoordeel: sy publikasielys kon tot tien volumes groei. Eers op sestig het sy groot werk, "Wahrheit und Methode", verskyn. Dit was maar sy tweede boek en dertig jaar na die eerste geskryf (Grondin 2000:13). As hy vroeg gesterf het, was daar min wat ons aan Gadamer kon herinner het. Volgens eie getuienis het hy maar swaar aan die skryf gekom. En as hy die dag geskryf het, het hy heeltyd die gevoel gehad Heidegger loer oor sy skouer (Gadamer 1993:491).

Gadamer is op die elfde Februarie gebore. Rene Descartes is weer op 11 Februarie 1650 oorlede. Tussen 1650 en 1900 (Gadamer se geboortejaar) het die Cartesiaanse wetenskapsideaal hoogty gevier: die selfstandige, objektiewe ondersoeker wat met behulp van die regte metode heldere en klare uitsprake oor die werklikheid kon maak. In die Bybelwetenskap sou hierdie ideaal op verskillende maniere voortleef (Le Roux 1996: 41-56). Op 11 Februarie 1900 is die groot kritikus van hierdie wetenskapsideaal egter in Marburg gebore, aan die begin van ' $n$ eeu wat later die "eeu van die hermeneutiek" genoem sou word (Grondin 1999:11,15).

Hieronder word enkele aspekte van Gadamer se hermeneutiek aangeroer: sy siening in verband met metode, die eindigheid van menswees, die waarde van vooroordele, ensovoorts. Met behulp van Gadamer kan ons ons Suid-Afrikaanse Ou Testament-tradisie opnuut 
bedink. Vrae oor geskiedenis, metode, en verstaan word weereens relevant en Gadamer se hermeneutiek kan ons egter baie help. Hy kan ons perspektiewe en begrippe verskaf wat ons kan help om opnuut weer oor die basisvrae van ons Ou-Testamentiese wetenskap te besin (vgl Eissfeldt 1926:20-29; 1929:30-39).

\section{IN 'N METODE LÊ ONS HEIL NIE}

Gadamer het hom veral teen ' $n$ bepaalde soort westerse wetenskapsbeoefening verset (Thiselton 1980:293-310; De Knijf 1980:111-115). Kenmerkend van hierdie tipe wetenskap was die siening dat 'n subjek (eksegeet, Ou Testamentikus) 'n objek ('n teks, die geskiedenis) as 't ware aan sy ondersoek kan onderwerp; die beklemtoning dat kennis slegs deur objektiewe waarneming (van die oorsake en die gevolge van die geskiedenis, of van 'n teks se taal) verkry kan word; die aanvaarding dat 'n metode (vir historiese of teksondersoek) noodsaaklik vir kennisverwerwing is; die strewe na wetenskaplike waarhede wat vas en seker is; die verifikasie en die kontrolering van alle kennis (Tarnas 2000: 282-290).

' $n$ Kenmerk van Gadamer se hermeneutiek is die kritiek op ' $n$ metodebewustheid wat by die historisme en ook soms by die menswetenskappe voorkom. Uiteraard is ' $n$ metode belangrik. Indien iemand ' $n$ huis bou, is 'n plan van die struktuur, asook die werkswyse, essensieel. Daarsonder kan die huis nie gebou word nie. Nóg die plan, die struktuur of die werkswyse (metode) is egter die huis. Netso is dit met die geesteswetenskappe (en Bybelwetenskappe) gesteld: 'n metode is belangrik, maar dit kan nie waarheid verskaf nie (Grondin 2000:32-39). Gadamer het hom dus teen die neiging verset dat ' $n$ metode sekerhede, ontwyfelbare sekerhede, kan verskaf (Gadamer 1993:276-291; Derksen 1983:63). Volgens hom het hierdie positiwistiese metode-ideaal net te ver gegaan; dit het gebiede betree waar dit nie hoort nie en onbillike eise aan kennis, waarheid en ervaring begin stel (Gadamer 1990:9-15).

\section{DIT GAAN OM DIE LEWE}

In die hermeneutiek (van die Ou Testament) gaan dit nie primêr om 'n metode nie. Dit gaan om die lewe. Of anders gestel: ons lewens. Ons is van nature wesens wat interpreteer: die lewe, tekste, die verlede en nog baie ander dinge meer. En in hierdie proses van interpretasie kan geen metode die finale betekenis vir ons ontsluit nie. ' $n$ Metode is belangrik, maar dit het ook sy perke. Waar moet ons dan begin? By ons eie kleinmenswees (met sy vooroordele, sy verstaanshorison) en ons eie kleinbestaan (wat op verskillende maniere deur die gang van die geskiedenis, asook die "Wirkungsgeschichte" van die Bybelwetenskap bepaal is). Daarin lê die kiem van verstaan. In die volgende paragrawe 
word hierdie perspektief verder uitgebrei. Eers begin ons met die relasie "geskiedenis" en "lewe".

Geskiedenis en lewe, lewe en geskiedenis is onskeibaar. Geskiedenis handel oor die lewe, die gewone lewe van mense. In die studie van die geskiedenis word baie fasette van menswees belig. Geskiedenis is belangrik

“omdat zij (de geschiedenis) van alle wetenschappen het naast staat aan het leven zelf. Omdat haar vragen en haar antwoorden die zijn, welke het leven zelf stelt, aan den enkele en aan de gemeenschap. Omdat de kennis die men draagt van persoonlijk leven of van gemeenchapsleven onmerkbaar overgaat in geschiedenis... Haar groot levenswaarde ontleent de geschiedenis aan haar onverbreekbaar band met het leven zelf"

(Huizinga 1950:105).

Dilthey het ook op 'n besondere wyse die noue band tussen lewe en verlede oor en oor belig. Dit is eintlik eers in die omgang met die verlede dat ons iets van menswees en die lewe begryp:

"Wanneer de menselijke natuur zichself in haar werkelijkheid en macht wil bezitten, in de volheid van levende mogelijkheden die tot het menselijk bestaan behoren, dan kan ze dat alleen in het historisch bewustzijn... De totaliteit van de menselijke natuur ligt enkel in de geschiedenis; het individu is zich van die totaliteit van zijn natuur alleen dan bewust, is alleen dan werkelijk in het genot ervan, wanneer het de geesten van het verleden in zich verzamelt” (Van Nierop 1988:17).

Lewe en geskiedenis is deur ' $\mathrm{n}$ netwerk van lewensdrade onlosmaaklik aanmekaar verbonde. As ons egter oor "lewe en geskiedenis" praat, word hierdie twee begrippe op ' $n$ besondere manier in die denke van Gadamer geknoop: die lewe is histories bepaald, maar die lewe, ons lewens help ook om die geskiedenis (en ook tekste) te ontsluit. ' $n$ Belangrike "voorvereiste" vir verstaan, is die ervaring van jou eindigheid.

\section{BESEF EERS JOU EINDIGHEID}

In Dilthey se lewensfilosofie het hierdie eindigheid ' $\mathrm{n}$ belangriks rol gespeel. Hy wou die lewe in sy historiese bepaaldheid verstaan. In 'n brief aan graaf Yorck verwys hy na hulle gemeenskaplike strewe om inhoud aan die begrip "historiese bepaaldheid" te gee (Heidegger 1998:496-497). Heidegger sou die begrip "faktisiteit" hiervoor gebruik (Heidegger 1998:495-503). Hierby het Gadamer aangesluit. "Faktisiteit” dui gewoon op my eie kleinbestaan. Ek leef en bestaan in ' $n$ bepaalde konteks; verder leef ek elke dag hierdie bestaan van my. Ek kan nooit weghardloop daarvan nie of dit sommer net los nie (Grondin 2001c:83-88). Belangrik 
is dat my faktisiteit meespeel wanneer ek tekste lees of die geskiedenis van Israel bestudeer. Anders gestel: my verstaan word deur my faktisiteit bepaal. En omdat dit so is, kan verstaan nooit aan 'n (eksegetiese of historiese) metode verbind word nie. Verstaan mag nooit "vermetodeologiseer" word nie; verstaan mag nooit metodies bemiddel word nie. Waar dit binne die geesteswetenskappe gebeur, is dit niks anders as ' $n$ desperate poging om status in die oë van die ander wetenskappe te verkry nie (Grondin 2001b:152-159).

Met die idee van faktisiteit wou Heidegger enige poging om ' $n$ Archimedespunt binne die wetenskap te verkry, ondermyn. Die idee van ' $n$ tydlose, finale basis vir die (Ou Testamentiese) wetenskap is niks anders as ' $n$ vlug nie: ' $n$ vlug van jou eindigheid. Die gedagte dat daar êrens in die (Bybel-)wetenskap vaste waarhede bestaan, is teken van ' $n$ vergeetagtigheid: jy vergeet jou eie klein-mens-wees. Die soeke na vaste (teologiese) sekerhede is ' $n$ onbereikbare kognitiewe_ideaal: so ' $n$ sekerheid lê buite die eindige wetenskaplike (of teoloog of $\mathrm{Ou}$ Testamentikus) se greep. Die poging om onbetwyfelbare feite-waarhede in verband met Israel se geskiedenis te formuleer, word deur ons eie eindigheid ondermyn: as eindige mense beskik ons nie oor die vermoë om sodanige uitsprake te maak nie (vgl Oudemans 1988:54-89).

\section{DIE GEESTESWETENSKAPPE IS ANDERS}

Soos reeds gesê, het Gadamer hom veral teen die historisme en Dilthey se metodebewustheid gestel. Dilthey het byvoorbeeld hard probeer om ' $n$ metode vir die menswetenskappe te ontwerp. Daarmee wou hy die geesteswetenskappe meer aanvaarbaar maak; wou hy aan die eise van die natuurwetenskappe voldoen; wou hy geldige, kontroleerbare en wetenskaplike uitsprake oor die geskiedenis maak. Die probleem is dan dat daar telkens aan die eise van die metodes van die natuurwetenskappe gekonformeer is. Gadamer het dit egter oor en oor gestel: 'n metode, of dan die regte metode, mag nooit ' $n$ voorvereiste vir wetenskaplike geldigheid wees nie (Gadamer 1990:9-15).

Vir Gadamer was Helmholtz se 1862 Heidelberglesing oor die onderskeiding tussen natuur- en geesteswetenskappe geweldig belangrik. In die natuurwetenskappe gaan dit om wette en reëls wat deur logiese redenering of induksie afgelei word. In die menswetenskappe is dit anders gesteld: hier is 'n soort "artistieke induksie" aan die werk. 'n Soort kreatiewe aanvoeling vir die geskiedenis; ' $n$ soort skeppende omgang met die teks; 'n soort wetenskap wat wars is van die toepassing van vaste metodiese reëls of die formulering van wetmatighede (Gadamer 1990:1314). Gadamer het dus na ' $n$ waarheid of ' $n$ ervaring van die waarheid gestreef wat nie deur enige wetenskaplike metode gevat kan word nie. In die menswetenskappe soos filosofie, kuns en geskiedenis word "iets" of 
'n waarheid "ervaar" wat buite die greep van die wetenskaplike metode lê. Anders gestel: in die menswetenskappe (en Ou-Testamentiese wetenskap) word ' $\mathrm{n}$ waarheid gevind, wat nie metodies geverifieer of gekontroleer kan word nie. En dit is hierdie waarheid wat Gadamer wou herwin, wat hy uit die kloue van die gangbare wetenskappe wou red en waaraan hy universele geldigheid wou verleen (vgl Le Roux 1996:41-56).

\section{EINDIGHEID EN DIE WETENSKAP}

In die lig van bogenoemde wil ons dit weer eens beklemtoon: wetenskap en my konkrete lewe, geskiedenis en my kleinbestaan, teksverstaan en my faktisiteit is onlosmaaklik. Ons ken, verstaan, beskryf vanuit ons eie klein menswêreld. Dit is ons wetenskaplike vertrekpunt. Anders gesê: ons oneindige klein beperkte leefwêreld gaan ons verstaansproses rig. Kennis is daarom ook nooit los van ons-in-die-wêreld-wees nie; ons is in hierdie wêreld en ook onafskeidelik deel van ons eie kleinwêreldjie en nooit kan ons van ons faktisiteit loskom nie. En hierdie faktisiteit of eindigheid gaan ons help om iets van Israel se verlede te begryp; dit gaan ons lees en verstaan van $\mathrm{Ou}$ Testamenttekste rig. Ons-in-die-wêreld-wees is dus ' $\mathrm{n}$ belangrike voorvereiste vir ons verstaan (vgl De Knijff 1980:104-111; 137-145).

\section{VOOROORDELE HELP ONS OM TE VERSTAAN}

Aangesien ons leefwêreld die betekenis (van die geskiedenis en tekste) medebepaal, is iets soos vooroordele baie belangrik. Vooroordele help ons om te verstaan: "But the historian cannot purify himself of prejudice because he, like those he studies, belongs to and is a creature of history. Nor is this fact to be lamented, for it is history itself that prejudices the historian; and his prejudices, therefore, are the media by which history becomes accesible to him' (Weinsheimer 1985:170). Dit was juis Gadamer se probleem met die historisme wat alle vooroordele wou aflê en die regte metode wou volg sodat alle vooroordele hokgeslaan en objektiewe resultate verkry kon word. Hierdie strewe na ' $n$ vooroordeellose verstaan, was die gevolg van die Aufklärung se wetenskapsideaal: objektiwiteit het alle vooroordele uitgesluit (Gadamer 1990:276-281). Gadamer (soos Heidegger) het die belangrikheid van vooroordele egter opnuut beklemtoon: vooroordele is die voorwaarde van alle verstaan; dit skep ' $n$ bepaalde betekenisverwagting; dit vorm 'n soort vooraf-verstaan van die teks (Gadamer 1990:270-276).

Dit beteken nie dat eksegetiese metodes skielik onbelangrik geword het nie. Niemand word van 'n metode onthef nie. Elke Ou Testamentikus moet van sy metode rekenskap kan gee. Elke metode is egter histories bepaald. Of anders gesê: elke metode "herberg" 'n hele aantal vooroordele. 
Ons kan dit aan die hand van die historiese kritiek se verstaan van die Pentateug verduidelik (Le Roux 1997:401-423). Hierdie benadering rig die manier waarop die Pentateug bestudeer moet word; dit verwoord as ' $t$ ware die oortuigings, waardes en tegnieke wat in ' $n$ bepaalde groep Pentateugondersoekers leef; dit verskaf die apparaat (teorieë, konsepte en metodes) om die Pentateug te bestudeer. Dit beklemtoon verder dat die Pentateugtekste in verskillende leefwêrelde gestalte gekry het, dat die finale Pentateugteks maar net een moment in ' $n$ groot beweging verteenwoordig, dat tekswording en teksverstaan onafskeidelik is, ensovoorts.

Wanneer ons die Pentateug histories-krities benader, word ' $n$ hele boel vooroordele dus oorgeneem en in die teks ingelees. Ooreenkomstig hierdie vooroordele (inherent aan die historiese kritiek) word die wording van die Pentateug asook die betekenis daarvan op ' $n$ bepaalde manier beskryf. Meer nog: by die leser leef daar ook die verwagting dat die Pentateug in sy historiese gang beskryf kan word; dat die verskillende bronne of tradisielae waaruit dit bestaan, aangedui kan word; dat die boodskap van die Pentateug in sy historiese konteks vertel kan word.

Ons ontkom nie aan 'n metode nie, maar ook nie aan die vooroordele inherent aan die metode nie. Aan die een kant help die vooroordele (van die historiese kritiek) ons om iets van die Pentateug in sy historiese wording te vestaan, maar aan die anderkant beklemtoon dit ook weer die metode se beperktheid. Geen metode kan die volle waarheid in verband met die Pentateug bemiddel nie want dit is self histories bepaald.

\section{NIEMAND ONTSNAP DIE "WIRKUNGSGESCHICHTE" NIE}

' $n$ Teks word nooit finaal uitgelê en geskiedsinterpretasie nooit finaal afgesluit nie. In elke nuwe situasie word nuut en anders oor teks en geskiedenis nagedink. En al hierdie eeue lange interpretasies is vir Gadamer nie stowwerige argiefmateriaal of verouderde werke wat sinloos op boekrakke staan nie. Dit kan 'n mens help om te verstaan. Dit verskaf interpretasies waarvan ons nie geweet het nie of waarvan ons vergeet het. Gadamer noem hierdie voortdurende proses van interpretasie en herinterpretasie "Wirkungsgeschichte" (Ndl: "effectieve geschiedenis"; Eng: "effective history") (Gadamer 1990:305-312). Die "Wirkungsgeschichte" is 'n historiese beweging wat nou nog hier en nou (bewustelik of onbewustelik) die lees van tekste en die verstaan van geskiedenis beïnvloed (Gadamer 1990:346-352). ' $n$ Teks se verstaan word mede deur die geskiedenis van die interpretasies daarvan bepaal. 'n Mens kan nooit ' $n$ teks op sy eie of opsigself verstaan nie. Dit kan nooit los van die 
interpretasies daarvan begryp word nie: "Werken kunnen niet los gezien worden van die geschiedenis van hun effecten” (Oudemans 1980:56).

Uiteraard het dit konsekwensies vir ons verstaan van 'n teks. Ons is net nooit alleen nie want die teks se "verlede" praat in die eksegetiese proses mee. Verstaan is dus nie soseer ' $n$ objektiewe handeling van ' $n$ subjek nie, maar eerder ' $n$ proses waarin ons deel van ' $n$ teks se verstaansgeskiedenis gemaak word (Gadamer 1990:295). Ons word as 't ware in die geskiedenis van die uitleg ingetrek en een daarmee gemaak. Anders gestel: menswees (of: teoloogwees) is nooit los van die verlede nie; ons is aan die geskiedenis "onderworpe"; ons maak nie geskiedenis nie, maar die geskiedenis maak ons; die geskiedenis (die "Wirkungsgeschichte") rig daarom ons verstaan; dit help ons om tekste te kan begryp. In ' $n$ baie bekende aanhaling sê Gadamer dat die "Wirkungsgeschichte" meer syn as bewussyn is: "wirkungsgeschichtliches Bewusstsein ist mehr Sein als Bewusstsein" (Gadamer 1993:101). Geskiedenis (of dan die "Wirkungsgeschichte") penetreer as 't ware ons totale lewensbestaan so volledig dat ons nooit daarvan kan loskom nie.

' $n$ Teks en die geskiedenis kan op verskeidenheid van maniere verstaan word,.en met hierdie verskeidenheid van interpretasies moet ons bewustelik rekening hou. Gadamer illustreer dit aan die hand van die moderne teater. Alle belangrike dramas is al soveel keer opgevoer dat ' $n$ bepaalde interpretasietradisie ontstaan het. Wie ' $n$ bepaalde drama opvoer, het dus al hierdie interpretasiemoontlikhede tot sy/haar beskikking. Dit is egter belangrik om daarop te let dat al hierdie interpretasies vanuit die omgang met die dramateks gegroei het. Mettertyd het dit by wyse van spreke aan die teks vasgegroei. Wie hom/haar dus met die interpretasiegeskiedenis besig hou, is ook primêr met die teks besig. Deur hierdie interpretasiegeskiedenis (of navorsingsgeskiedenis) verkry die leser toegang tot die verstaan van die teks. Kortom: die talle interpretasies van ' $n$ teks (of die geskiedenis van Israel) kan 'n mens help om te verstaan (Gadamer 1990:124).

Bogenoemde beklemtoon opnuut Gadamer se radikale eindigheidsgedagte. En die uitdrukking "wirkungsgeschichtliches Bewusstsein" verwoord hierdie eindigheid. Daarmee word die bewuswording van ons eie perke beskryf; word die bewussyn van ons eie eindigheid beklemtoon. Iemand met so ' $n$ bewussyn is nie meer so naïef om te dink hy/sy weet wat in die teks staan nie. Of wat werklik in die verlede gebeur het nie. Telkens wanneer ons na die eintlike boodskap van 'n teks of die ware historiese gebeure streef, haal ons eindigheid (of faktisiteit) ons in. Elke interpretasie sit maar net op die een of ander manier die "Wirkungsgeschichte" verder voort. 


\section{HORISONNE ONTMOET MEKAAR}

Wat gebeur wanneer ons tekste of die geskiedenis probeer verstaan? (Marquard 1991:116-146). In 'n moeilike (selfs problematiese) gedeelte skryf Gadamer oor ons verstaanshorison. ' $\mathrm{n}$ Horison is alles wat ek om my kan sien wanneer ek op ' $n$ bepaalde punt staan en rondkyk (Gadamer 1990:305-312). Iemand met ' $n$ beperkte horison kan by wyse van spreke nie ver sien nie; hy kan net die naby-dinge sien en daaroor praat. Iemand met ' $n$ wye horison kyk verby die naby-dinge en sien die dinge op die verre horisonne raak. En alles wat hy sien, word dan in ' $\mathrm{n}$ geheelvisie ingebind. So is dit ook met my verstaanshorison gesteld. Ek leef binne ' $n$ bepaalde konteks, ek het sekere vooroordele (oor, sê maar, die Pentateug), ek word deur die kragte van die geskiedenis gevorm en my verstaan van tekste en die geskiedenis word deur die "Wirkungsgeschichte" bepaal. Hierdie lewenskonteks, en alles wat dit mag inhou, vorm my verstaanshorison. Vanuit hierdie lewensruimte kyk ek as 't ware ware na dinge (soos geskiedenis en tekste) en gee ek volgens my verstaanshorison betekenis daaraan. En my horison kan uiteraard wyd of eng wees, maar hoe dit ook al sy, dit is met behulp van my verstaanshorison dat ek aan tekste en die geskiedenis sin gee (Gadamer 1990:375-384).

Vir die historisme (en Dilthey) was “my verstaanshorison” ' $\mathrm{n}$ groot probleem. Vir hulle was objektiwiteit die groot ideaal. Vooroordele moes afgelê en die regte metode moes gevolg word. En as ek die verlede (van Israel) bestudeer, moes ek as 't ware uit my verstaanshorison tree en in die wêreld van Israel se verlede inklim. Volgens hulle moes ek my "huis" (my leefwêreld) verlaat en in ander vreemde "woning" (die geskiedenis) gaan bly. Dit sal my dan die nodige objektiwiteit verleen om gesaghebbende uitsprake oor die geskiedenis te maak.

Dit is nie hoe dit volgens Gadamer moet gebeur nie. Ek neem my verstaanshorison saam as ek die geskiedenis bestudeer ("Der Horizont ist vielmehr etwas, in das wir hineinwandern und das mit uns mitwandert"). Dit kan ook nie anders nie want vanuit my horison "skep" ek die horison van die geskiedenis. Verstaan is wanneer my verstaanshorison en die geskiedshorison mekaar ontmoet; wanneer die horison-van-nou met die horison-van-toe saamsmelt ("Vielmehr ist Verstehen immer der Vorgang der Verschmelzung solcher vermeintlich für sich seiender Horizonte") (Gadamer 1990:309,311). Historiese verstaan het dus alles met my wêreld (of dan my verstaanshorison) te make: vanuit my leefwêreld kry ek toegang tot die verlede; vanuit my verstaanshorison skep ek die horison van die geskiedenis en gee ek aan die verlede sin. En ek verstaan eers die verlede wanneer my horison en die van die verlede (wat ek self gemaak het) versmelt. 
Uit bogenoemde is ' $n$ paar sake dinge nou duidelik:

- Die geskiedenis maak nie maklik “oop” nie. Dit is vol weerstand, absurditeit en onbegryplikhede. Dit is ' $\mathrm{n}$ duister boek en tevergeefs soek ons na die een allesomattende betekenis (“... das Buch der Geschichte [ist] für jede Gegenwart ein im Dunkel abbrechendes Fragment” - Gadamer 1990:203).

- Alle geskiedenis loop deur ons. Dit is die enigste manier waarop ons sin van die verlede (of van ' $n$ teks) kan maak. Hierdie betekenis is deur ons faktisiteit gevorm, deur ons vooroordele geslyp en vanuit ons verstaanshorison sin gegee. Geen geskiedenis is enigsins naastenby ' $n$ rekonstruksie van die vergange werklikheid of ' $n$ weergawe van hoe dinge werklik gebeur het nie.

๑ 'n Mens kan nooit 'n "gelyktydigheid" met die vergange tyd bereik nie. Niemand het onmiddellike toegang tot die verlede nie en niemand kan volkome een (in tyd) met historiese figure voel nie. Geen historikus (lees: Ou Testamentikus) kan bokant sy/haar eie eindigheid (sy/haar vooroordele en sy/haar verstaanshorison) uitstyg om die verlede in sy naakte waarheid te kan verstaan en te beskryf nie. Soos ons gesê het: alles loop deur ons, en in die sparteling om alles by ons verstaanshorison te laat inpas, het ons die verlede al vuil gevat. So vuil dat die verlede in baie opsigte obskuur geword het.

a Die geskiedenis verwerp alle eenduidigheid. Historiese verstaan het met meerduidigheid te make. Daar is nie net een regte verstaan of betekenis van Israel se verlede nie. As elke historikus (of $\mathrm{Ou}$ Testamentikus) se leefwêreld vir hom/haar die geskiedenis (van Israel) ontsluit, is veelvuldigheid die konsekwensie (vgl Van Niekerk 1992:31).

- Ons moet daarom leer om met die teks (van die Ou Testament) en die geskiedenis (van Israel) te speel. In die spel verkrummel die subjek-objek-verhouding. Wanneer daar gespeel word, kan die spelers nie die spel (die teks, die geskiedenis) tot objek verding nie. Nooit kry die spelers beheer daaroor nie en nooit kan die speler die spel manipuleer nie. Eintlik gebeur die teenoorgestelde: die spel is die heer, die "subjek" wat alles oorheers. Dit verlok, verlei die speler om deel te neem, dit trek hom nader, dit betrek hom by die spel en dit hou hom besig (Gadamer 1990:108,112). 
Soos ons gesê het, Gadamer kan ons help met die taal en terminologie, insigte en perspektiewe om oor geskiedsverstaan en teksinterpretasie te praat. Sy hermeneutiek kan ons help om ons spreke oor die Ou Testament en die geskiedenis van Israel te verfyn. Sy denke kan ons help om dit waarmee ons besig is, helderer te formuleer.

\section{Literatuurverwysings}

De Boer, Th (red) 1988. Hermeneutiek. Meppel/Amsterdam: Boom.

De Knijff, H W 1980. Sleutel en slot. Kampen: Kok, 104-111, 137-145.

Derksen, L D 1983. On universal hermeneutics. Amsterdam: VU Boekhandel, 63.

Eissfeldt, O 1926. The history of Israelite-Jewish religion and Old Testament theology, in Ollenburger, Martens \& Hasel 1992, 20-29.

-, 1929. Does Old Testament theology still have independent significance within Old Testament scholarship, in Ollenburger, Martens \& Hasel 1992, 30-39.

Figal, G 2000. Begegnungen mit Hans-Georg Gadamer. Stuttgart: Phillip Reclam jun.

Gadamer, H-G 1990. Wahrheit und Methode. Tübingen: JCB Mohr, 124.

-, 1993. Hermeneutik II. Tübingen: JCB Mohr, 276-291.

Grondin, J 1999. Hans-Georg Gadamer. Tübingen: J. C. B. Mohr, 11,15.

-, 2000. Einführung zu Gadamer. Tübingen: J C B Mohr, 32-39.

-, 2001a. Der Sinn für Hermeneutik. Darmstadt: Wissenschaftliche Buchgesellschaft

-, 2001b. Einführung in die Philosophische Hermeneutik. Darmstadt: Wissenschaftliche Buchgesellschaft.

-, 2001c. Von Heidegger zu Gadamer. Darmstadt: Wissenschaftliche Buchgesellschaft.

Heidegger, M 1998. Zijn en tijd. Nijmegen: SUN, 496-497.

Huizinga, J 1950. Verzamelde werken, VII. Haarlem: H D Tjeenk Willink, 105.

Le Roux J H 1996. Eksegese is 'n spel. Acta Theologica, 16/1, 41-56.

-, 1997. Our historical heritage. OTE 10/3, 401-423.

Marquard, Odo 1991. Abschied vom Prinzipiellen. Stuttgart: Philipp Reclam jun, 116146.

Ollenburger, B C, Martens, E A \& Hasel, G 1992. The flowering of Olf Testament Theology. Winona Lake: Eisenbrauns.

Oudemans, Th C W 1988. Gadamers wijsgerige interpretatieleer, in De Boer, Th (red). Hermeneutiek. Meppel/Amsterdam: Boom, 54-89.

Schmid, K 1999. Erzväter und Exodus. Neukirchen-Vluyn: Neukirchener Verlag.

Tarnas, R 2000. The passion of the western mind. London: Random House, 282-290.

Thiselton, A C 1980. The two horizons. Exeter:Paternoster, 293-310; De Knijff, H W 1980. Sleutel en slot. Kampen: Kok, 111-115.

Van Niekerk, A 1992. Rasionaliteit en relativisme.

Van Nierop, M 1988. Leven en historiciteit: De hermeneutica van Dilthey, in De Boer, 1988:17.

Van Seters, J 1999. The Pentateuch. A social-science commentary. Sheffield: Sheffield Academic Press.

Weinsheimer, J C 1985. Gadamer's hermeneutics. New Haven: Yale University Press, 170 - my beklemtoning.

Zenger, E (red) 1998. Einleitung in das Alte Testament. Stuttgart: W Kohlhammer. 